\title{
O ISS E A EXPORTAÇÃO DE SERVIÇO
}

\section{Leandro Cara Artioli ${ }^{1}$}

\section{RESUMO}

O presente estudo constrói um dos significados do conceito de "resultado" do serviço prestado a tomador no exterior, sob o ponto de vista da teria das classes e categorias de semiótica, e sua influência na hipótese de incidência do Imposto Sobre Serviço - ISS, previsto no art. 156, inciso II, da Constituição Federal. Através da teoria das classes e da experiência colateral de Peirce, são utilizados termos lógicos para classificação da hipótese de incidência do ISS, e para classificação dos fatos que estão foram do campo de incidência do tributo, especificamente nos casos de serviços exportados ao exterior. Nestas hipóteses, a Constituição Federal outorgou a competência ao legislador complementar para regular quais são os fatos juridicamente relevantes para fins de incidência ou não do ISS. A partir desse sistema de referência, o significado do conceito de resultado se apresenta distante do conceito de conclusão, sendo mais próximo do significado de fruição.

Palavras Chave: ISS. Exportação de Serviço. Resultado

\footnotetext{
1 Advogado. Mestrando em Direito Tributário pela Pontifícia Universidade Católica de São Paulo (PUC-SP). Especialista em Direito Tributário pela Pontifícia Universidade Católica de São Paulo. Bacharel em Direito pela Universidade Católica Dom Bosco.
} 


\section{SUMMARY}

This study builds one of the concepts of "result of the service" to borrowers abroad, from the point of view of Class Theory and semiotic categories, and it influences on the Service Tax - ISS, in accordance with article 156, II, of the Federal Constitution. This study uses logical terms of Class Theory, in order to classify the taxable facts and to classify the facts that are not in the field of ISS, specifically in the case of services abroad. In these cases, the Federal Constitution grants the power for the legislator to regulate the facts that are not in the field of ISS. According to Class Theory and collateral experience from Peirce, the meaning of the concept of "result" differs from the concept of "conclusion", being closer to the concepts of enjoyment or fruition.

Palavras Chave: ISS. Service Exports. Results

\section{INTRODUÇÃO}

No âmbito da competência tributária dos municípios o ISS é, sem dúvida, o de maior relevância para fins arrecadatórios, com impacto não só na tributação local, mas também em âmbito internacional, capaz de influenciar organizações societárias complexas.

As normas que disciplinam o ISS apresentam conceitos vagos e imprecisos que merecem ser analisados com a devida atenção, principalmente quando se trata de prestação de serviços ao exterior.

A perspectiva fática sobre o tema impõe quatro situações distintas: (i) o prestador brasileiro realiza a atividade psicofísica (fazer) com resultado comprovado no território nacional, cujo produto é encaminhado ao tomador no exterior; (ii) prestador brasileiro realiza a 
atividade psicofísica materializada no território nacional, porém sem resultado comprovado, e é encaminhada para o tomador no exterior onde o resultado pode ser comprovado; (iii) prestador brasileiro inicia a atividade psicofísica iniciada no território nacional, a qual é concluída no exterior, local onde produz resultado, e é encaminhado ao tomador; (iv) prestador brasileiro realiza a atividade psicofísica materializada no exterior, onde o prestador possui presença comercial ou não, e é encaminhada ao tomador também no exterior.

As discussões sobre possíveis exportações de serviços ficam limitadas às duas primeiras hipóteses, já que o fato gerador nas hipóteses seguintes não possuem relação com o território brasileiro.

A análise da incidência do ISS nas exportações de serviço não decorre de simples técnica, mas prescinde da interpretação do sistema jurídico, impregnado de valores e limites impostos pela Constituição Federal.

\section{Hermenêutica APLiCAda}

A hermenêutica é a ciência que estuda os diversos tipos de interpretação. No caso dos serviços exportados, o ISS pode ser analisado sob o prisma político, econômico, social, lógico, finalístico e outros, mas não se pode partir de outro sistema de referência senão o texto legal.

Art. $1^{o}$ O Imposto Sobre Serviços de Qualquer Natureza, de competência dos Municípios e do Distrito Federal, tem como fato gerador a prestação de serviços constantes da lista anexa, ainda que esses não se constituam como atividade preponderante do prestador.

Art. $2^{\circ}$ O imposto não incide sobre:

I - as exportações de serviços para o exterior do País; 
Parágrafo único. Não se enquadram no disposto no inciso I os serviços desenvolvidos no Brasil, cujo resultado aqui se verifique, ainda que o pagamento seja feito por residente no exterior.

A interpretação do texto no plano mais simples de intelecção, permite criar duas premissas importantes: (a) serviço prestado a tomador estrangeiro: o resultado é determinante para fins incidência do ISS; (b) serviço prestado a tomador no território nacional: o resultado é indiferente.

No Brasil a política tributária estimula as exportações como fomento industrial e comercial do mercado internacional, buscando maior representatividade do país no contexto mundial e atraindo investimentos estrangeiros. Embora essa análise decorra das ciências políticas, no âmbito normativo o art. $3^{\circ}$, inciso II da Constituição Federal permite identificar os valores que devem influenciar toda atividade legislativa, sempre com o objetivo de buscar o desenvolvimento nacional.

A interpretação das normas tributárias, principalmente aquelas que se voltam às relações com investimento estrangeiro, devem sempre ser valoradas conforme o art. $3^{\circ}$, inciso II, da Carta Constitucional.

No âmbito constitucional o ISS é construído não só pelo critério material (prestação serviços de qualquer natureza - exceto de transporte intermunicipal e interestadual e de comunicação), mas também o critério territorial.

O ISS é tributo cujo fato jurídico pode ultrapassar os limites territoriais do sujeito competente para instituí-lo. Embora a legislação tenha delimitado a eficácia jurídica do imposto ao perímetro territorial de cada um dos municípios, a complexidade do fato gerador pode, muitas vezes, causar conflitos de competência ou até mesmo dúvida sobre a incidência ou não da 
norma tributária, considerando o disposto no parágrafo único do art. $2^{\circ}$ da Lei Complementar $n^{\circ}$ 116/03, conforme será visto a diante.

No caso dos tributos de competência da União, a maioria dos problemas de interpretação se resolve pela análise do critério material. Contudo, no âmbito da competência dos Estados, Distrito Federal e Municípios, além da delimitação material do fato jurídico tributário, o critério territorial restringe a incidência do tributo apenas às hipóteses que ocorram nos limites (físicos) estaduais, distritais ou municipais (à exceção do ICMS, que possui contornos de uniformidade nacional, por expressa previsão constitucional).

$\mathrm{O}$ art. $2^{\circ}$ da Lei Complementar $\mathrm{n}^{\circ} 116 / 03$, com fundamento de validade no inciso II, $\S 3^{\circ}$ do art. 156 da Constituição Federal estabelece claramente que não incidirá ISS nos serviços prestados ao exterior. Como complemento, o parágrafo único leva ao entendimento de que o serviço que, de alguma forma, tenha o resultado auferido no exterior, não será hipótese de incidência da norma tributária.

A fenomenologia da incidência normativa, principalmente quando envolve aspectos fáticos cujos elementos são vagos e imprecisos - como a prestação de serviços ao exterior, não é compreendido por simples intuição jurídica. Decorre, sim, do fluxo contínuo do raciocínio sobre as normas previstas pelo sistema.

\section{O RESUlTAdo DA HiPóteSE DE INCIDÊNCIA dO ISS}

Ao isolar a norma jurídica do campo das ciências, em interessante estudo Kelsen toma-a como objeto estritamente jurídico e explica que seu âmbito de incidência circunscreve uma espécie de moldura ${ }^{2}$ linguística, na qual podem ser encontrados os conceitos jurídicos (elementos internos). No processo interpretativo o sujeito não poderia ultrapassar os limites semânticos estabelecidos por aquela moldura, isto é, não poderia alterar a definição dos conceitos que

${ }^{2}$ KELSEN. Hans. Teoria Pura do Direito. São Paulo. Martins Fontes:2015. p. 388.

http://revistasapereaude.org/index.php/edicoes/ano-5-volume-1-agosto-2016

153 
compõem seus significados comuns. Nesse sentido, quanto mais vagas e ambíguas são as expressões utilizadas no texto legal, maior é a moldura normativa, pois os conceitos ganham maior amplitude semântica. Por outro lado, quando mais precisas são as expressões utilizadas pelo legislador, menor é a moldura e a interpretação é restrita.

Evidente que não se pretende, aqui, isolar a visão normativa e lhe atribuir o caráter absoluto para fatalmente cair no normativismo exacerbado, entendido como "algo excessivo, que se põe logo em franca competição com outros esquemas de compreensão, afastando iniciativas epistemológicas que se dirigem aos diferentes setores de que se compõe o fenômeno"3.

Para fins de objeto de estudo, toma-se por base o art. 156, inciso III, da Constituição Federal. Nele é possível identificar a moldura que o legislador municipal, sujeito passivo da norma de competência, deve respeitar ao instituir o ISS. O fato gerador que os Municípios podem eleger como suficientes e necessários para instituir esta espécie tributária é o serviço. Sobre o fato gerador previsto na Constituição Federal, Aires F. Barreto explica que " $a$ Constituição (art. 156, III) refere ao fato serviço e, necessariamente - embora de modo implícito seu produtor. Não sup̃̃e o fato com abstração de quem lhe dá a vida". Prossegue o citado doutrinador ensinando que "só a prestação do serviço é tributável, porque o conteúdo econômico indica o prestador como o verdadeiro beneficiário da retribuição que, de alguma maneira, é o modo objetivo de mensuração desse mesmo conteúdo econômico"4.

Como regime de exceção, a Constituição Federal reservou ao legislador complementar a competência para excluir de sua incidência exportações de serviços para o exterior no art. $156, \S 3^{\circ}$, inciso II, da Constituição Federal.

\footnotetext{
${ }^{3}$ CARVALHO. Paulo de Barros. Direito Tributário Linguagem e Método, São Paulo. 3a . Edição. Noeses: 2015. P. 127

${ }^{4}$ Aires F. Barreto. ISS na constituição e na lei. $3^{\text {a }}$ Ed. Dialética. 2009 . p.31.

http://revistasapereaude.org/index.php/edicoes/ano-5-volume-1-agosto-2016 
Embora o fato tributável seja a prestação de serviço de qualquer natureza, o art. $2^{\circ}$, inciso I da Lei Complementar $n^{\circ} 116 / 03$, retirou do âmbito de incidência as exportações de serviços para o exterior, exceto nas hipóteses em que o resultado é auferido no Brasil. O parágrafo único do citado dispositivo trata da exceção às hipótese de incidência do ISS, nos seguintes termos: "não se enquadram no disposto no inciso I [não incidência] os serviços desenvolvidos no Brasil, cujo resultado aqui se verifique, ainda que o pagamento seja feito por residente no exterior".

Diferentemente do fato gerador do ISS - prestação de serviço - que independe do resultado, fruição ou utilização, quando a Constituição Federal autorizou o legislador complementar a retirar do âmbito da incidência do ISS as exportações de serviços ao exterior, pretendeu estimular o desenvolvimento nacional em várias frentes das políticas micro e macroeconômicas.

O legislador complementar foi influenciado pela política de comércio exterior prevista no art. $3^{\circ}$, inciso II, da Constituição Federal, no momento que fez uso de sua competência constitucional, ao excluir a prestação de serviço por tomador residente no exterior do âmbito de incidência do ISS. Assim, o fato juridicamente relevante para a hipótese de incidência do ISS nestas hipóteses é o resultado verificado no exterior.

Se o resultado é verificado no território nacional, o serviço é considerado prestado no Brasil e o imposto incide, mas quando o resultado é verificado no exterior, o fato "prestar serviço" é irrelevante juridicamente. Trata-se de conceitos distintos a partir da mesma expressão constitucional, porém com aberturas semânticas diferentes, porque formam duas normas distintas - a que constitui a hipótese de incidência e a que exclui da hipótese o elemento "resultado".

Adotando categorias teóricas para descrever, no mundo científico, os fenômenos jurídicos (já que a incidência é construção lógica de implicação e inclusão de classes), pode-se 
compreender a fenomenologia da incidência do ISS aos serviços exportados através da teoria das classes, ou também chamada de teoria dos conjuntos.

Tarek Moysess Moussalem explica que "a classe não se encontra na realidade física, é construção intelectiva. Não vemos a classe. Criam-se, linguisticamente, classes" ${ }^{5}$, distinguindo-as de seus elementos. No processo de classificação o intérprete seleciona propriedades de um ou mais objetos, cujo conceito é formado conforme seus horizontes culturais, e estabelece vários critérios de diferenciação ${ }^{6}$.

Esses critérios permitem encontrar os elementos, ou indivíduos, conforme ensina $\operatorname{Tarski}^{7}$, que se identificam com o conceito e, portanto, pertencem à classe conotada. Classes e elementos formam conceitos específicos e com utilidades distintas ${ }^{8}$.

O objeto desta análise se subdivide em duas hipóteses distintas, uma em que há a incidência e outra em que a legislação complementar excluiu do campo normativo o mesmo fato jurídico. Para esta segunda hipótese foi incluído um específico elemento a ser considerado em caso de tomador residente no exterior: resultado do serviço.

\section{Hipótese de Incidência}

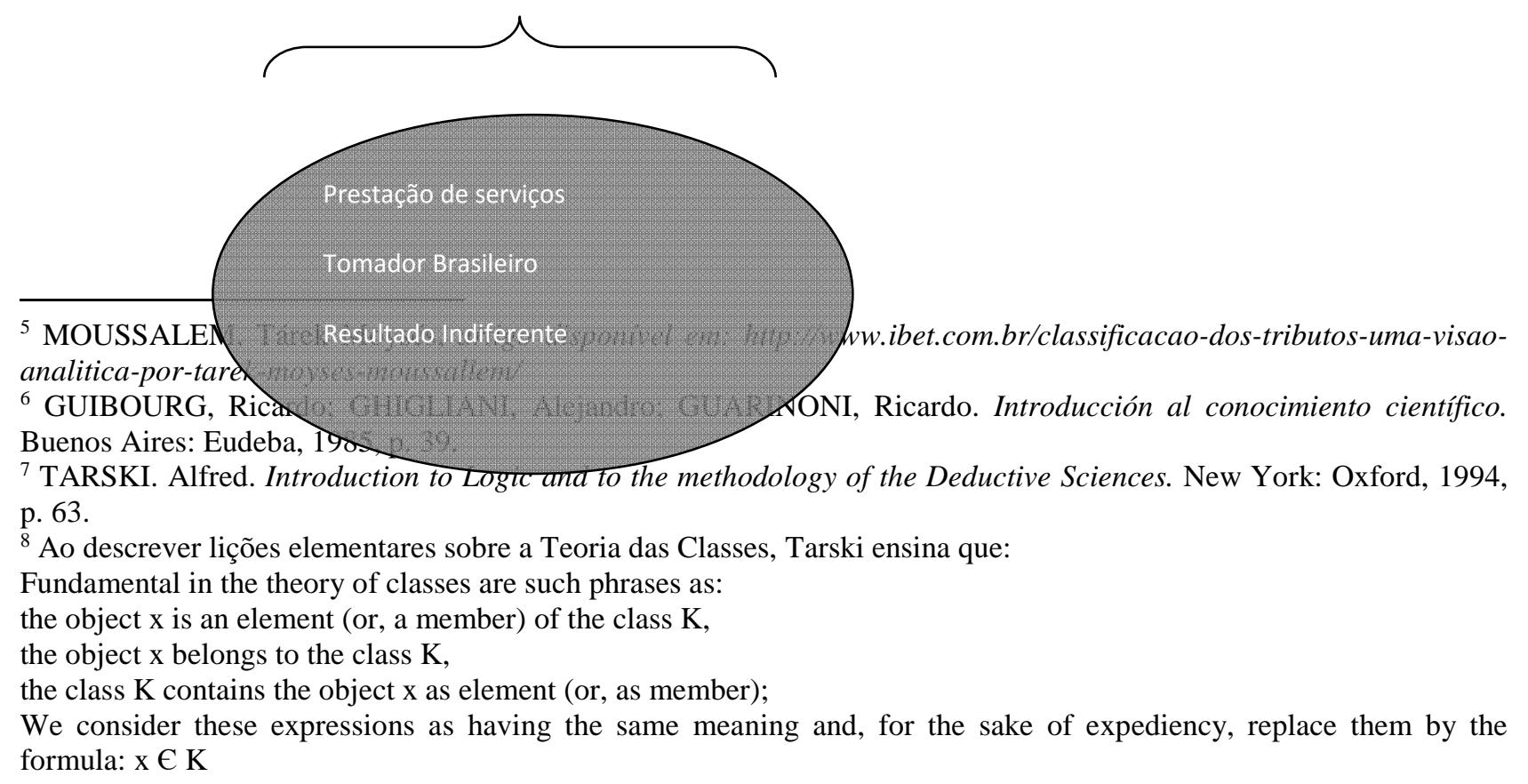

We consider these expressions as having the same meaning and, for the sake of expediency, replace them by the
formula: $x \in \mathrm{K}$

http://revistasapereaude.org/index.php/edicoes/ano-5-volume-1-agosto-2016

D.O.I: 10.20523/sapereaude-ano5-vol-1-pg-149-159 


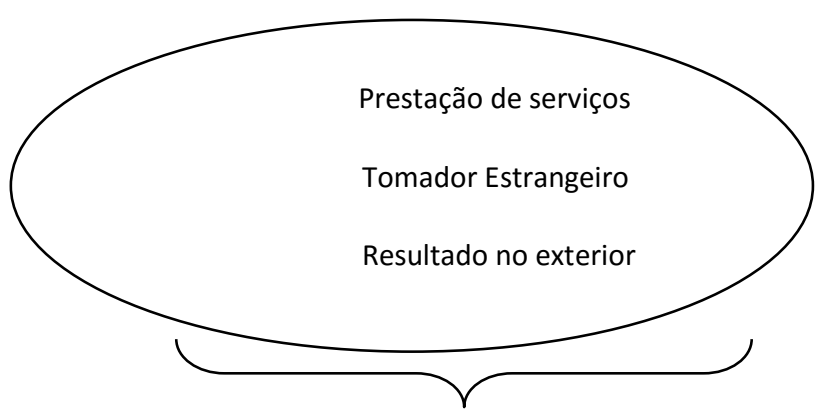

Hipótese de Não-Incidência

Sistematizando as duas classes de normas que se interseccionam (aplicáveis aos serviços prestados no Brasil e aos serviços exportados com resultado no exterior), é possível identificar os elementos em comum, exceto a hipótese de exportação de serviço, que apresenta elemento disjuntor.

O elemento disjuntor das duas classes (prestação de serviço no Brasil e prestação de serviço exportado) é o resultado verificado pelo tomador no exterior. Se o resultado é no Brasil, o fato jurídico está sujeito à incidência do ISS. Por outro lado, quando o resultado do serviço prestado é verificado no exterior, está fora do campo de incidência.

Para conceituar a expressão "resultado" é necessário buscar sua significação através daquilo que Peirce chama de experiência colateral ${ }^{9}$. A experiência colateral é a intimidade prévia com a denotação daquilo que se pretende conhecer, contido na cultura intérprete. Trata-se da intersecção entre o que é conhecido e o que ainda pode ser conhecido.

Ao relacionar o termo "resultado" no triângulo semiótico, prestigiando o que se aproxima do conceito da palavra (experiência colateral), é possível concluir que seu significado é semelhante à "fruição", "efeito" ou "consequência". A adoção destes significados à expressão contida no parágrafo único do art. $2^{\circ}$ da Lei Complementar $n^{\circ}$ 116/03 também foi adotada pelos ministros da $1^{\text {a }}$ Turma do Superior Tribunal de Justiça no julgamento do REsp n. 831.124.

\footnotetext{
${ }^{9}$ PEIRCE, Charles Sanders. Collected Papers. 8. vol. Cambridge, MA: Harvard University Press, 1966. p. 642.
} 
Ocorre que nas operações comerciais a "conclusão" e o "resultado" podem causar conflitos de entendimento entre o fisco municipal e contribuinte. Com efeito, o local onde o resultado do serviço pode ser verificado não é necessariamente o mesmo de sua conclusão. As expressões "resultado e conclusão" não podem ser utilizadas como sinônimos, pois o serviço pode ser fisicamente concluído no território nacional pelo prestador, porém, o resultado surtir efeito no exterior pelo tomador.

O local da conclusão do serviço é aquele em que a atividade psicofísica é finalizada. É o local onde a atividade desenvolvida pelo prestador não se faz mais necessária, tendo em vista a conclusão do objeto da relação jurídica contratual com o tomador. A conclusão de um serviço nem sempre se confunde com o local físico onde é materializado o fazer, evento no qual o comprova empiricamente.

Por essa razão, a interpretação do conceito de "resultado" deve ser aquela que se aproxima da ideia de desenvolvimento nacional através da participação do país no mercado internacional. A ideia é tentar evitar que os tributos se tornem custo do exportador e sejam agregados ao preço do serviço, para tornar o serviço brasileiro mais acessível e competitivo no cenário internacional. Daí porque o local do resultado do serviço é aquele em que o serviço poderá ser usufruído.

Tal regra foge do conceito de local do estabelecimento prestador como elemento definidor do sujeito ativo do ISS, por expressa previsão legal (art. $2^{\circ}$ da Lei Complementar $n$. 116/03). No caso de serviços exportados a fruição verificada fora do território nacional afasta a incidência do ISS (embora não haja alteração do fato gerador, que continua sendo prestar serviço).

A jurisprudência não é pacífica, mas já sinaliza importantes precedentes favoráveis aos contribuintes ao interpretar corretamente a expressão "resultado", no âmbito 
administrativo e judicial, que podem ser utilizados para afastar a tributação de algumas operações com o exterior.

\section{Referências}

BARRETO. Aires F.. ISS na constituição e na lei. $3^{\text {a }}$ Ed. Dialética. 2009.

CARVALHO. Paulo de Barros. Direito Tributário Linguagem e Método, São Paulo. $3^{\text {a }}$. Edição. Noeses: 2009.

KELSEN. Hans. Teoria Pura do Direito. São Paulo. Martins Fontes:2015.

PEIRCE, Charles Sanders. Collected Papers. 8. vol. Cambridge, MA: Harvard University Press, 1966. 